\title{
Efeito do manejo alimentar no desempenho do matrinxã Brycon amazonicus em tanques de cultivo
}

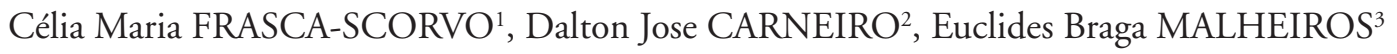 \\ RESUMO \\ O objetivo deste estudo foi avaliar o efeito do horário, taxa e freqüência de alimentação no desempenho do matrinxã (Brycon \\ amazonicus) em tanques de cultivo. O trabalho foi realizado no Centro de Aqüicultura da UNESP, Jaboticabal, SP, no período \\ de outubro de 1997 a janeiro de 1998 sendo realizados três ensaios, em tanques de $200 \mathrm{~m}^{2}$ subdivididos em 4 de $50 \mathrm{~m}^{2}$. No \\ ensaio I foram medidos em 3 períodos (manhã-m; meio do dia-md e tarde-t) o consumo de ração, índice de ingestão, tempo \\ de saciação e velocidade de ingestão em peixes com peso médio de $232,13 \mathrm{~g}$, alimentados com ração extrusada (32\% de PB). \\ Não foi observada diferença significativa nos parâmetros analisados. No ensaio II, em peixes com peso médio de $233,98 \mathrm{~g}$, \\ foi medido o consumo médio de ração, em intervalos de duas horas, das 07 às 19 horas. $\mathrm{O}$ maior consumo ocorreu quando o \\ matrinxã foi alimentado às 17 horas. No ensaio III, durante 57 dias, os peixes foram alimentados uma vez ao dia $(\mathrm{m})$; uma vez \\ ao dia $(\mathrm{t})$; duas vezes ao dia $(\mathrm{m} / \mathrm{t})$ e três vezes ao dia $(\mathrm{m}, \mathrm{md}, \mathrm{t})$. Peixes com peso médio inicial de $322,25 \mathrm{~g}$ receberam ração com \\ $32 \%$ de PB, na quantidade de $2 \%$ do PV. Não foram observadas diferenças significativas no ganho de peso diário $(3,17 ; 2,80$; \\ 3,04 e 2,81 g) e na conversão alimentar aparente $(2,11 ; 2,48 ; 2,16$ e 2,31:1). Concluiu-se que a frequiência de alimentação de \\ uma vez ao dia, em qualquer horário, mostrou ser suficiente.
}

PALAVRAS-CHAVE: Matrinxã, Brycon, freqüência de alimentação, taxa de alimentação, desempenho produtivo.

\section{Effect of the feed management on performance of Matrinxã Brycon amazonicus in rearing ponds}

\begin{abstract}
The objective of this study was the identification of effect of period, number of meals, ration feed and frequency of feeding on performance of Matrinxã Brycon amazonicus. The work was carried out on the Aquaculture Center of UNESP in Jaboticabal, SP. The observations were accomplished in three stages, from October 1997 to January 1998 in 16 ponds of $50 \mathrm{~m}^{2}$. In the first stage it was analyzed the feed consumption, ingestion index and satiation time. Fishes with initial average weight of $232.13 \mathrm{~g}$ were fed extruded ration of CP $32 \%$ in three different periods of the day: morning, noon and afternoon. No significant differences were observed. In second stage the feed consumption was observed in two hours intervals from 7 AM to 7 PM. Fishes previous mean weight of $233.98 \mathrm{~g}$ was used. The statistical analysis demonstrated that the greater consumption happened when the matrinxã was fed at 5 PM. In the third stage feeding frequency was tested (once a day: in the morning; once a day: in the afternoon; twice a day, in the morning and afternoon; three times a day: in the morning, noon and afternoon) during 57 days. Fishes with initial average weight of $322.25 \mathrm{~g}$ were fed extruded commercial pellets with $32 \%$ of CP at a $2 \%$ biomass rate. No statistical differences were found in weight daily gain $(3.17 ; 2.80 ; 3.04 ;$ and $2.81 \mathrm{~g})$ and in food conversion rate $(2.11 ; 2.48 ; 2.16$ and $2.31: 1)$. In order to support growth the results showed that it is enough to feed matrinxã once a day despite the feeding time.
\end{abstract}

KEYWORDS: Matrinxã, Brycon, Feeding frequency, Biomass rate, Performance

\footnotetext{
1 Pesquisadora científica - APTA- Pólo Leste Paulista.,SAA. e-mail: cfrasca@apta.sp.gov.br

2 Prof. Dr. do Departamento de Zootecnia da FCAVJ/UNESP e CAUNESP/UNESP

${ }^{3}$ Prof. Dr. do Departamento de Ciências Exatas da FCAVJ/UNESP
} 


\section{INTRODUÇÃO}

A piscicultura, enquanto atividade zootécnica teve na última década, emergente desenvolvimento, exigindo assim estudos de nutrição e de alimentação das espécies nativas de interesse comercial, para tornar-se uma atividade economicamente viável, e de importância para o país.

O matrinxã ou matrinchã é o nome popular do Brycon amazonicus e segundo Lima, (2003) sua distribuição na América do Sul, se dá no rio Amazonas e alguns tributários brasileiros sendo que, esta espécie até 2003, vinha sendo denominada de Brycon. ceplhalus que só ocorre no alto do Rio Amazonas no Peru e Bolívia.

O matrinxã e de grande importância econômica na Bacia Amazônica e, ocupa os primeiros lugares nos desembarques de Manaus e Porto Velho, Graef et al. (1993) e de acordo com Brandão et al (2007) o matrinxã é a segunda espécie mais criada na região Amazônica e Hoshiba et al (2007) relata que só perde para o tambaqui e que sua criação na década de 90 cresceu devido suas características que incluem excelente sabor da carne e comportamento agressivo, tornando se espécie de interesse pelos pescadores. Esta espécie é também, muito procurada pelos pesqueiros espalhados pelo Estado de São Paulo, para a pesca esportiva (Scorvo Filho et al., 1998). De acordo com Goulding (1980), a espécie é onívora e segundo Izel et al. (1996), em cativeiro, aceita rações peletizadas e extrusadas, bem como subprodutos agroindustriais.

Pesquisas sobre a atividade de alimentação segundo Jobling et al. (1983), têm importância prática sob vários pontos de vista e podem ampliar os conhecimentos sobre o ritmo de alimentação dos peixes, contribuindo assim para uma melhor utilização do alimento, levando a uma produção mais eficiente.

A obtenção de um manejo alimentar adequado de uma espécie, depende de um conjunto de fatores que influenciam a ingestão dos alimentos tais como: quantidade e qualidade do alimento, tamanho, textura, cor, propriedades organolepticas do alimento, temperatura da água, oxigênio dissolvido, horário de arraçoamento, frequiência e ritmo de alimentação, sistema de criação, teor de proteína e energia da ração. Muitos estudos foram realizados sobre os mecanismos que regulam a ingestão de alimentos, tempo de transito gastro- intestinal, identificação e detecção do alimento foram realizados por Ivlev,(1961); Bret, (1971); Vahl, (1979); Cowey,(1981); Cho, (1992) e também, Simpson e Raubenheimer, (2001) propõem uma estrutura conceitual e experimental para estudos de ingestão de macronutrientes (proteína,carboidrato e lipídios) em peixes. Também, foram realizadas muitas investigaçōes sobre a alimentação do matrinxã em cativeiro, sendo que, Saint-Paul e Werder (1977) realizaram os primeiros trabalhos investigando a alimentação, e outros autores realizaram investigaçôes relacionadas à alimentação na natureza e a nutrição da espécie:
Cyrino et al (1986), Borgethi et al, (1991), Izel et al. (1996), Gomes et al (2000); Pezzato et al (2000), Pizango-Paima et al (2001), Salum et al (2002), Izel et al (2004), Hoshiba et al (2007). Sobre o comportamento alimentar da espécie, FrascaScorvo et al (2001) realizaram um estudo analisando o manejo alimentar nos meses de temperaturas mais baixas.

O manejo alimentar adequado pode proporcionar uma produção sustentável tanto ecológica como econômica, pois pode diminuir a descarga de nutrientes em seus efluentes,bem como, produzir um peixe com um menor custo de produção, pois de acordo com Scorvo Filho et al. (2004) a alimentação tem um grande peso no custo variável. No entanto poucos são os dados na literatura sobre praticas da alimentação do matrinxã e, com vistas à obtenção de coeficientes técnicos para melhor desempenho do matrinxã, este estudo teve como objetivo, avaliar o efeito do horário, taxa e frequêencia de alimentação no desempenho do matrinxã (Brycon amazonicus) em tanques de cultivo

\section{MATERIAL E MÉTODOS}

O trabalho foi realizado no Centro de Aqüicultura da UNESP (CAUNESP), Campus de Jaboticabal, na região nordeste do Estado de São Paulo, no período de outubro de 1997 a janeiro de 1998, quando foram realizados três ensaios.

Foram utilizados quatro tanques, de $200 \mathrm{~m}^{2}$, com profundidade mínima de 1,0 e máxima de $1,5 \mathrm{~m}$, paredes revestidas de alvenaria e fundo de terra. Esses tanques foram subdivididos em quatro repartições de $10,0 \mathrm{~m}$ x 5,0 m (50 $\mathrm{m}^{2}$ ), com telas plásticas de malha de $15 \mathrm{~mm}$, totalizando 16 parcelas. $\mathrm{O}$ abastecimento era por derivação da água captada de uma represa, passando antes por um filtro de cascalho e tela plástica. No período de 29 de outubro a 10 de novembro de 1997, foram realizados os ensaios I e II para investigar o consumo de ração, o tempo de saciação e o índice de ingestão em três períodos do dia.

No ensaio I, os resultados obtidos para consumo de ração por peixe $(\mathrm{g})$, tempo de saciação $(\mathrm{min})$, velocidade de ingestão (g/min) e o índice de ingestão (\%), em cada período do dia, foram analisados para os seguintes tratamentos:

T1 - fornecimento de ração, das 8:00 às 10:00 h, (manha-m), T2 - fornecimento de ração, das 10:30 às 15:00 $\mathrm{h}$, (meio do dia-md), T3 - fornecimento de ração, de 15:30 às 18:00 h, (tarde-t). Avaliando os seguintes parâmetros:

a) consumo de ração por peixe (Cs): $\mathrm{Cs}=\mathrm{Qr} / \mathrm{Npx}$ : onde: $\mathrm{Qr}$ = quantidade de ração e $\mathrm{Npx}=$ número de peixes.

b) Índice de Ingestão Alimentar (IA): IA $(\%)=(\Sigma \mathrm{Cs} / \mathrm{Pm})$ $\mathrm{x} 100$, onde: $\mathrm{Cs}=$ consumo médio de ração; $\mathrm{Pm}=$ peso médio.

c) tempo de saciação (TS): obtidos como a média do tempo de 
fornecimento de ração em minutos, em cada tratamento.

d) velocidade de ingestão $(\mathrm{VI})(\mathrm{g} / \mathrm{min})=\mathrm{Cs} / \mathrm{TS}$, onde: $\mathrm{Cs}=$ consumo médio de ração e TS = tempo de saciação.

Foram utilizados 800 peixes, com peso médio de $232,13 \mathrm{~g}$ $( \pm 0,95)$, na densidade de um peixe. $\mathrm{m}^{-2}$, totalizando 50 peixes por subdivisão do tanque.

Os animais passaram por um período de cinco dias de adaptação e condicionamento para alimentação dentro de comedouros em forma de aros, construídos de PVC de 2" e tela plástica de $15 \mathrm{~cm}$ de altura, para obter-se um maior controle da quantidade ingerida. Após o término do período de adaptação, foi iniciado o ensaio I, com observações sobre ingestão de alimento e tempo de saciação em três períodos do dia. Os peixes foram alimentados com ração comercial extrusada, contendo $32 \%$ de proteína bruta. O controle da oferta de ração nos três períodos do dia foi realizado em um tanque a cada dia.

A ração foi oferecida à vontade, até que encerrasse a procura pelo alimento, e anotado o tempo e a quantidade de ração fornecida. Quando havia sobra da ração oferecida, esta era retirada com puçá de malha fina, seca em estufa durante 36 horas, e pesada para posterior desconto na determinação da quantidade do alimento ingerido.

Neste ensaio foi utilizado o delineamento em blocos casualisados, com três tratamentos e quatro repetições, considerando-se cada tanque um bloco e as subdivisôes como repetições dentro de blocos. A análise estatística dos resultados deste ensaio foi realizada através do teste $\mathrm{F}$ para análise de variância e, teste de Tukey para comparação de médias, ao nível de $5 \%$ de probabilidade.

Com a finalidade de se conhecer os melhores horários de alimentação, em termos de consumo de ração, foi realizado o Ensaio II. Foram utilizados 800 peixes oriundos do ensaio I, com peso médio de $233,98 \mathrm{~g}( \pm 5,60)$ na mesma densidade utilizada no ensaio anterior. A ração foi oferecida à vontade, dentro dos aros alimentadores, sendo utilizada a mesma ração do ensaio I, e as sobras retiradas da mesma forma. Os diferentes horários de fornecimento de ração constituíram os tratamentos: T1 - fornecimento de ração às 7:00 h, T2 - fornecimento de ração às 9:00 h, T3 - fornecimento de ração às 11:00 h, T4 - fornecimento de ração às 13:00 h, T5 fornecimento de ração às 15:00 h, T6 - fornecimento de ração às 17:00 h, T7 - fornecimento de ração às 19:00 h.

Neste ensaio foi utilizado o delineamento inteiramente casualizado, com sete tratamentos e quatro repetiçōes. A análise estatística dos resultados deste ensaio foi realizada através do teste $\mathrm{F}$ para análise de variância e, teste de Tukey para comparação de médias, ao nível de 5\% de probabilidade.

Com base nos resultados observados nos ensaios anteriores, foi conduzido o III ensaio, para avaliar o crescimento e desempenho do matrinxã, quando submetidos a diferentes frequiências de alimentaçáo. Este ensaio foi realizado no período de 18 de novembro de 1997 a 14 de janeiro de 1998, totalizando 57 dias de observação.

Foram utilizados 800 peixes, provenientes dos ensaios anteriores, com peso médio de 322,25g ( $\pm 5,60)$. Em cada parcela foram estocados 50 peixes, na densidade de um peixe. $\mathrm{m}^{-2}$.

Inicialmente os peixes passaram por um período de cinco dias de adaptação aos tanques, e foram alimentados com ração comercial extrusada, contendo $32 \%$ de proteína bruta.

A partir do cálculo dos índices de ingestão, realizados no ensaio II, foi determinada a taxa de alimentação de $2 \%$ do peso vivo de cada parcela.

Foram testados quatro tratamentos: T1 - alimentação uma vez ao dia, (m), T2 - alimentação uma vez ao dia, (t), T3 alimentação, duas vezes ao dia, (m) e (t) e T4 - alimentação três vezes ao dia: manhã $(\mathrm{m}),(\mathrm{md})$ e tarde $(\mathrm{t})$, com quatro repetiçôes.

Durante o período experimental foram realizadas biometrias de uma amostra de $30 \%$ dos peixes, aos 28 e 57 dias, e os valores médios de peso aos 28 dias foram utilizados para os cálculos dos reajustes da quantidade de ração a ser fornecida no período subseqüente.

Foram avaliados os seguintes parâmetros de desempenho de produção em cada parcela experimental:

- ganho em peso: calculado pela diferença entre a média de peso dos peixes no início e ao final do período experimental;

- conversão alimentar aparente: calculada pela relação entre a média de consumo de ração e média de ganho em peso;

- taxa de crescimento específico: T.C.E $=\ln \mathrm{Ptf}-\ln \mathrm{Pti} /$ tempo de experimento (dias) $\mathrm{x} 100$

Onde: $\mathrm{Ptf}=$ peso total final, $\mathrm{Pti}=$ peso total inicia, $\ln$ -logaritmo natural (base e)

As medidas de temperatura da água foram registradas diariamente, em todos os horários de alimentação. A cada dez dias, durante o período experimental, foram monitoradas as condiçōes ambientais do cultivo, em quatro tanques, um de cada tratamento, escolhido aleatoriamente, sempre por volta das 9h00 da manhã, dos seguintes parâmetros: $\mathrm{pH}$, medido com peagametro portátil; transparência da água, através do disco de Secchi; oxigênio dissolvido, determinado pelo método de Winkler; alcalinidade total, medida por titulação, como recomendado por Golterman et al (1978); condutividade elétrica, lida em condutivímetro portátil e amônia total, analisada espectrofotometricamente, de acordo com o método descrito por Solarzano (1969) citado por Baptista (1987).

$\mathrm{O}$ delineamento experimental utilizado foi inteiramente 
casualizado, composto por quatro tratamentos com quatro repetições e 50 peixes por parcela. A análise estatística dos resultados foi realizada através do teste $\mathrm{F}$ para análise de variância, e teste de Tukey para comparação de médias, ao nível de 5\% de probabilidade.

\section{RESULTADOS E DISCUSSÃO}

\section{ENSAIO I - CONSUMO DE RAÇÃO, ÍNDICE DE INGESTÃO ALIMENTAR, TEMPO DE SACIAÇÃO E VELOCIDADE DE INGESTÃO EM TRÊS PERÍODOS DO DIA.}

Os valores médios de consumo de ração por peixe, tempo de saciação e índice de ingestão alimentar, estão apresentados na Tabela 1.

Embora o consumo de ração no período da tarde tenha sido maior, o teste $\mathrm{F}$ para a análise de variância não apontou diferenças estatísticas significativas em todas as variáveis analisadas. De forma contraria aos resultados deste experimento, Maragoudaki et al. (1997) verificaram para o Pagrus pagrus uma alta demanda de alimento no período da manhã. Dias (1998) observou em um experimento com juvenis de pacu, em condiçōes de laboratório, a influência do período de alimentação no consumo alimentar da espécie, indicando que a quantidade de ração ingerida pelos peixes alimentados no período da tarde foi $64,5 \%$ maior do que os alimentados no período da manhã.

Os índices de ingestão nos diferentes períodos estudados também não apresentaram diferenças significativas. Com relação ao índice de ingestão do Heteropneutes fossilis, Shing e Srivastava (1985) constataram uma relação sigmóide com o tempo de saciação, e o índice de ingestão não excedeu a $1,73 \%$ do peso corporal.

Neste estudo os valores dos índices de ingestão alimentar determinado foram semelhantes aos indicados por Schimittou (1993), de 2 a 3\% do peso vivo, para alimentação da tilápia, carpa e bagre do canal, e também se assemelham àqueles

Tabela 1 - Valores de F, coeficiente de variação (CV) e médias obtidas na análise de variância para, consumo ração por peixe(Cs/px), índice de ingestão alimentar (IA) e o tempo de saciação (TS) em três períodos do dia - Ensaio I.

\begin{tabular}{lccc}
\hline \multicolumn{4}{c}{ Variáveis } \\
\hline Estatística & $\begin{array}{c}\text { Cs/px } \\
(\mathrm{g})\end{array}$ & $\begin{array}{c}\text { IA } \\
(\% \text { do PV })\end{array}$ & $\begin{array}{c}\text { TS } \\
(\mathrm{min})\end{array}$ \\
\hline F para Tratamento & 1,29 Ns & $1,23^{\text {Ns }}$ & $2,12^{\text {Ns }}$ \\
CV(\%) & 79,19 & 80,77 & 49,05 \\
\hline Médias & & & \\
T1- M & 2,47 & 1,08 & 24,90 \\
T2- MD & 2,86 & 1,26 & 18,50 \\
T3- T & 3,88 & 1,69 & 25,96 \\
\hline
\end{tabular}

recomendados por Kubitza (1997); para espécies de peixes tropicais na fase de recria e engorda de 1 a $3 \%$ do peso vivo, variando de acordo com a temperatura da água.

Os valores médios do tempo de saciação (Tabela 1) não foram estatisticamente diferentes. Shing e Srivastava (1985) determinaram para o Heteropneutes fóssili, média de 44,44 min. No entanto, segundo Ishiwata (1968), o tempo médio para atingir a saciação de Trachurus japonicus foi de 65 minutos, e para Salmo gardneri foi 60 minutos. Brett (1971) determinou para Oncorhynchus nerka, o tempo médio de 43 minutos. Nagata (1989) determinou o tempo médio de 60 minutos para o Oncorhynchus maso., Os valores determinados por esses autores são elevados quando comparados com os resultados obtidos para o matrinxã, e poucos são os trabalhos citados na literatura com espécies de peixes de água doce em relação aos parâmetros da alimentação, especialmente quanto ao tempo gasto. Assim, os resultados obtidos no presente estudo não permitiram comparação com outros autores. Por outro lado, de acordo com Dias (1998), os valores do tempo de saciação do pacu determinado em condiçôes de laboratório, em temperatura constante de $23^{\circ} \mathrm{C}$, no período da manhã foi de 6,58 minutos, e para a temperatura de $27^{\circ} \mathrm{C}$ foi de 9,78 minutos. No período da tarde o autor encontrou valores de 7,75 e 7,94 minutos, para as duas temperaturas estudadas, respectivamente.

As médias da velocidade de ingestão, nos três períodos do dia, calculadas a partir do tempo de saciação foram: $\mathrm{m}=0,10 \mathrm{~g}$. $\mathrm{min}^{-1} ; \mathrm{md}=0,15 \mathrm{~g} \cdot \mathrm{min}^{-1}$ e $\mathrm{t}=0,14 \mathrm{~g} \cdot \mathrm{min}^{-1}$.

Contudo, apesar de serem considerados peixes vorazes, o presente trabalho mostrou que o matrinxã é menos ávido pelo alimento quando comparado com o pacu, segundo Dias (1998), que determinou a velocidade de ingestão do pacu, nos períodos da manhã e da tarde como sendo $0,56 \mathrm{~g} / \mathrm{min}$ e 0,73 $\mathrm{g} / \mathrm{min}$, respectivamente quando a temperatura da água era $23^{\circ} \mathrm{C}$, e para temperatura de $27^{\circ} \mathrm{C}$, foram $0,46 \mathrm{~g} /$ min período da manhã e $1,00 \mathrm{~g} / \mathrm{min}$ à tarde.

\section{ENSAIO II - HORÁRIOS DE PROCURA POR ALIMENTAÇÃO}

Os valores médios de consumo de ração, observados em diferentes horários do dia, são apresentados na Tabela 2.

$\mathrm{O}$ teste $\mathrm{F}$ para a análise de variância demonstrou diferenças estatísticas significativas ao nível de $0,01 \%$ de probabilidade. $\mathrm{O}$ teste de comparação de médias demonstrou que a maior procura baseada no consumo médio de ração, ocorreu quando o matrinxã foi alimentado entre 15 e 17 horas. Entretanto, não havendo diferenças estatísticas $(\mathrm{P}>0,05)$ do consumo entre as 11 e 19 horas, onde o arraçoamento mostrou ser mais eficiente em todo o período, indicando a preferência pelo horário de alimentação no período da tarde. A preferência de alimentação por este período pode estar relacionada, além de outros fatores, à maior variação da quantidade de oxigênio dissolvido na 
Tabela 2 - Valores de F, coeficiente de variação(CV) e médias obtidas na análise de variância para, consumo de ração por tanque, em diferentes horários do dia - Ensaio II.

\begin{tabular}{lc}
\hline Estatística & Consumo médio(g) \\
\hline F para Tratamento & $10,16^{\star \star}$ \\
CV(\%) & 41,44 \\
\hline Médias para os horários: & \\
T1- 7h & $2,81^{\mathrm{d} 11}$ \\
T2- 9h & $3,63^{\mathrm{cd}}$ \\
T3- 11h & $6,04^{\mathrm{abc}}$ \\
T4- 13h & $5,12^{\mathrm{abc}}$ \\
T5- 15h & $7,43^{\mathrm{ab}}$ \\
T6- 17h & $7,62^{\mathrm{a}}$ \\
T7- 19h & $6,93^{\mathrm{ab}}$ \\
DMS2 & 2,17 \\
\hline
\end{tabular}

1- Valores seguidos da mesma letra, na coluna, não diferem estatisticamente entre si pelo teste de Tukey, ao nível de $5 \%$ de probabilidade.

${ }^{2}$ diferença mínima significativa (DMS)

água durante o dia, que segundo Vinatea-Arana (1997), as concentrações de oxigênio dissolvido da água são muito baixas e, durante o dia, os níveis elevam-se até um máximo, devido quase que totalmente aos processos fotossintéticos.

Por outro lado, o efeito do horário de alimentação no metabolismo da proteína, para truta arco-íris, foi pesquisado por Gelineau (1994) que observou baixa performance de crescimento dos peixes alimentados à noite em relação aos alimentados ao amanhecer.

Estudos realizados por Dias Jr e Mourgues-Schurtler (1996) com Leporinus obtusidens demonstraram que o melhor horário de fornecimento de ração para esta espécie foi às 10 horas, com um período de disponibilidade de 4 horas. Jarboe e Grant (1996) não observaram influência do horário de alimentação no desempenho do bagre do canal, a não ser para a porcentagem de gordura visceral, mostrando diferenças estatisticamente significativas para esses valores. Webster et al. (1992a; 1992b) trabalhando com a mesma espécie, encontraram resultados similares, onde também não puderam observar a influência do horário de alimentação no desempenho de produção dos peixes.

\section{ENSAIO III - FREQÜÊNCIA E HORÁRIO DE ALIMENTAÇÃO.}

A temperatura média da água dos tanques, durante o ensaio de freqüência e horário de alimentação variou de $20^{\circ} \mathrm{C}( \pm 7,80)$ a $35^{\circ} \mathrm{C}( \pm 8,32)$ e estiveram acima do intervalo citado por Guimarães e Storti-Filho (1997) para o desenvolvimento dessa espécie que vai de $18^{\circ} \mathrm{C}$ a $36^{\circ} \mathrm{C}$, aproximadamente.

Os valores médios observados para os parâmetros físicoquímicos da água durante este ensaio foram: transparência $55 \mathrm{~cm}( \pm 5) ; \mathrm{pH} 8,0( \pm 0,03)$; oxigênio dissolvido 3,20 mg. $\mathrm{l}^{-1}$ $( \pm 0,25)$ alcalinidade total $25,33 \mu \mathrm{g} . \mathrm{l}^{-1}( \pm 0,63)$; condutividade elétrica $50 \mu \mathrm{S} . \mathrm{cm}^{-1}( \pm 3,31)$; amônia total $0,77 \mu \mathrm{g} \cdot \mathrm{l}^{-1}( \pm 0,10)$.
Durante o período experimental, não foram detectadas grandes variações nos parâmetros monitorados, e se mantiveram dentro das amplitudes consideradas satisfatórias para o bom desenvolvimento dos peixes de acordo com Boyd (1990), Castagnolli (1992) e Vinatea-Arana (1997).

No entanto, os teores de oxigênio dissolvido da água dos tanques apresentaram variaçōes, principalmente no segundo período experimental, atingindo valores considerados baixos para o cultivo de peixes (Boyd, 1990). De acordo com Soares (1989), o matrinxã pode sobreviver em águas com teores de oxigênio dissolvido mais baixos que outras espécies de zona temperada poderiam suportar.

Os valores médios de consumo de ração, ganho de peso, e conversão alimentar aparente são apresentados na Tabela 3.

$\mathrm{O}$ teste $\mathrm{F}$ para a análise de variância não demonstrou haver diferenças significativas $(P>0,05)$ com relação ao ganho de peso, consumo e conversão alimentar aparente do matrinxã, submetidos a diferentes freqüências de alimentação.

Em estudos realizados por Van Der Meer et al. (1997), com alevinos de tambaqui, o aumento da freqüência de alimentação resultou em aumento significativo da ingestão e da taxa de crescimento específico. No entanto, quando a freqüência de alimentação passou de três para cinco vezes ao dia, foi observado um aumento de apenas $3 \%$ na taxa de crescimento e houve uma diminuição de $10 \%$ na conversão alimentar aparente. Os autores citam que a freqüência de alimentação de três vezes ao dia, resultou em diminuição no coeficiente de variação para os dados de peso final do tambaqui, causada possivelmente, pela diminuição da competição entre os indivíduos.

Essa resposta ao comportamento alimentar foi observada também por Jobling (1983), em investigação realizada sobre o efeito da freqüiência de alimentação na ingestão e crescimento do Salvelinu alpinus "arctic charr", mostrando que o crescimento dessa espécie pode ser afetado pela interação social e pela dominância hierárquica entre os indivíduos, e o aumento na freqüência de alimentação pode reduzir os efeitos desses fatores.

Tabela 3 - Valores de F, coeficiente de variação (CV) e médias obtidas na análise de variância para consumo de ração(g)-(Cs), ganho peso diário(g)-(GP/dia) e conversão alimentar aparente-(CAA) Ensaio III.

\begin{tabular}{lccc}
\hline Estatística & Cs & GP/dia & CAA \\
\hline F para tratamentos & $0,65^{\mathrm{NS}}$ & $0,78^{\mathrm{NS}}$ & $0,74^{\mathrm{NS}}$ \\
CV $(\%)$ & 3,79 & 13,79 & 16,79 \\
\hline Média & & & \\
T1- M & 378,88 & 3,17 & 2,11 \\
T2- T & 380,68 & 2,80 & 2,48 \\
T3- M+T & 371,83 & 3,04 & 2,16 \\
T4- M+MD+T & 368,38 & 2,81 & 2,31 \\
\hline
\end{tabular}


Shing \& Srivastava (1984) demonstram que alevinos de bagre africano com peso inicial de 6,84g a 8,83g, quando alimentados duas vezes ao dia, apresentaram máxima taxa de crescimento específico e melhor taxa de conversão alimentar aparente. Buurma e Diana, 1994 em um estudo com Clarias fuscus, $(37 \mathrm{~g})$ verificaram que os peixes alimentados três vezes ao dia, cresceram 19\% mais rápido que os alimentados uma vez ao dia e com peixes $(78 \mathrm{~g})$, os animais alimentados duas vezes ao dia cresceram $47 \%$ mais rápido que os alimentados uma vez ao dia, indicando que o desenvolvimento destes peixes em resposta a variações na freqüência alimentar depende muito da espécie, do tamanho, da ração fornecida e das condiçôes de cultivo. O mesmo deve ter ocorrido com o bagre do canal, estudados por Jarboe e Grant (1996) que não observaram diferenças significativas na taxa de crescimento específico do bagre do canal, submetido a diferentes freqüências de alimentação.

Os valores médios de ganho de peso diário do matrinxã (Tabela 4) se mostraram superiores aos obtidos por Saint-Paul e Werder (1977), 0,5g/dia, em um experimento realizado com a mesma espécie, utilizando ração granulada. Os resultados deste experimento assemelharam-se aos valores obtidos por Mendonça et al. (1993) 3,69 e 2,91g/dia e aos de Romagosa et al. (1998), de 2,97g/dia. Pezzato et al (2000) obtiveram um ganho de peso diário de 1,27 a 1,37g/dia e concluíram que as variaçōes térmicas que ocorreram, influenciaram no desempenho do peixe. Já Izel et al (2004) obteve um ganho de peso de $4 \mathrm{~g}$ por dia nos peixes alimentados com ração com teor de $28 \%$ de $\mathrm{PB}$. As diferenças observadas podem ser atribuídas às distintas condiçōes de cultivo e diferentes manejos alimentares adotados.

A conversão alimentar aparente nos diferentes tratamentos foram semelhantes aos resultados observados por outros pesquisadores com a mesma espécie, Saint-Paul e Werder (1977) 2,77:1; Mendonça et al. (1993) 1,99 e 2,33:1; Izel et al (1996) 2,77, 3,12 e 3,44:1 e; Fosse et al. (1997) de 2,50 a 2,20:1, Romagosa et al. (1998) 2,40 a 2,00:1; Izel et al (2004) 2,04 a 2,17:1. Apenas Honczaryk (2000) relatou melhores resultados de conversão alimentar $(1,88,1,56$ e 1,82:1) em um estudo sobre o efeito da densidade de estocagem $(1,3$, e 5 peixes. $\left.\mathrm{m}^{-2}\right)$, respectivamente no crescimento do matrinxã criados em viveiros.

Os valores da taxa de crescimento específico observado para o matrinxã neste experimento foram: T1 $(0,79)$; T2 $(0,70)$, $\mathrm{T} 3(0,67)$ e T $4(0,72)$ foram semelhantes àqueles encontrados em estudos realizados com matrinxã por Mendonça et al. (1993) 0,72 a 0,80 em média e, superiores aos obtidos por Carvalho et al. (1997) que foram de 0,41 a 0,54 em média.

\section{CONCLUSÕES}

O horário de maior consumo de ração ocorreu às 17 horas, coincidindo com o horário em que ocorrem maiores concentraçōes de oxigênio dissolvido na água e, pode-se sugerir que a alimentação seja feita neste horário.

Podemos sugerir a taxa de alimentação determinada, para esta espécie, nas condições deste estudo, que foram de 1,08 (m); 1,26(md) e 1,69(t) \% do peso vivo.

Considerando o manejo alimentar adotado neste trabalho, o desempenho de produção observado para o matrinxã demonstrou que o arraçoamento pode ser realizado a só uma vez ao dia, refletindo, nesta fase de desenvolvimento, uma grande interação social e até a capacidade digestiva, aparentemente sem dominância hierárquica, o que atrapalharia o crescimento.

Outros estudos devem ser conduzidos sobre o manejo alimentar do matrinxã, principalmente envolvendo os efeitos de diferentes taxas de alimentação sobre o desempenho de produção e aspectos econômicos relacionados ao cultivo em tanques.

\section{BIBLIOGRAFIA CITADA}

Baptista, J. M. R.; Baumgarten, M. G.; Niencheski, L. F. H. (ed). 1987. Caderno de Análises em Oceanografia Quimica. Editora FURG, Rio Grande, RS. p. 50-52.

Borgethi, J.R.; Canzi, C.; Nogueira, S.V.G.1991. A influencia da proteína no crescimento do matrinchã (Brycon orignyannus) em tanques-rede. Revista Brasileira de Biologia, 51(3);695-699.

Boyd, C.E. 1990. Water Quality in Ponds for Aquaculture. Ala. Agr. Exp. Sta., Auburn Univ., Alabama. USA 482pp.

Brandão, F.R.; Gomes, L.C.; Chagas, E. C.; Araújo, L. D.; Silva, A. L. S. 2005. Densidade de estocagem de matrinxã (Brycon amazonicus) na recria em taque-rede. Pesq. Agropec. Bras, 40(3): 299-303.

Brett, J.R. 1971. Satiation time appetite and maximum food intake of sockeye salmon Oncorhynchus nerka. Fish. Res. Board Can, 28: 409-415.

Buurma, B.J.; Diana, J.S. 1994. Effects of feeding frequency and handling on growth and mortality of cultured walking Catfish Clarias fuscus. Journal of the World Aquaculture Society, 25: 175-182.

Carvalho, R.A.P.L; Ferraz de Lima, J.A.F.; Silva, A.L.N. 1997. Efeito da densidade de estocagem no desempenho do matrinchã, Brycon cephalus (Günther, 1869), cultivado em tanques-rede no período de inverno. B. Inst. Pesca, São Paulo, 24: 177-185.

Castagnolli, N. 1992. Criação de Peixes de Água Doce. Jaboticabal, FUNEP, 189pp. 
Dias Jr, W.; Mourgués-Schurtler, L. R. 1996 . Determinação do horário de fornecimento de ração e o tempo de alimentação da espécie Leporinus obtusidens, Valencienes, 1847 (Ostheichthies, Anastomidae). Anais do IX Simpósio Brasileiro de Aqüicultura, Sete Lagoas, MG. p. 89.

Cho, C.H.1992. Feeding systems for rainbow trout and other salmonids whith reference to current estimates of energy ando protein requirements. Aquaculture, 100: 107-123

Cowey, C.B. 1981. The food and feeding of captive fish. In: A.D. Hawkins (ed) Aquarium Systems Academic Press, London. p.223-246.

Cyrino, J.E.P.; Castagnolli,N.; Pereira-Filho,M. Digestibilidade da proteína de origem animal e vegetal pelo matrinxã (Brycon ceplhalus GÜNTHER, 1869) Euteleostei,Chacaciformes, Char acidae). Anais do V Simpósio Brasileiro de Aquiicultura.Cuiabá, p.49-62.

Dias, T. C. R. 1998. Efeito da temperatura de cultivo na fisiologia da digestão e metabolismo do Pacu, Piaractus mesopotamicus (HOLMBERG, 1887). Tese Doutorado, SP. Centro de Aqüicultura da Universidade Estadual Paulista, 77pp.

Fosse, P. J.; Martin, S.; Verani, J. R.; Antunes, S. A. 1997. Growth response of adult matrinxã, Brycon cephalus (GÜNTHER, 1869), to different alfafa hay levels as dietary fiber in Pirassununga, SP, Brasil. Anais do Internacional Symposium Biology of Tropical Fishes, Manaus, AM. p.132.

Frascá-Scorvo,C. M. D.; Carneiro, D. J.; Malheiros, E. B. 2001. Comportamento alimentar do matrinxã Brycon Cephalus (GÜNTER, 1869) no período de temperaturas mais baixas. Bol. do Inst.de Pesca vol.27(1): 1-5.

Gelineau, A.1994. Effects of feeding time on protein metabolism in rainbow trout, Oncorhynchus mykiss, Bordeaux-France, Univ.Bordeaux-I, France, 32pp.

Golterman, H. L.; Clymo, R. S. e Ohnstad, M. A. M. 1978. Methodos for physical and chemical analysis of freshwater. 2 ed. Oxford: Blacwell Science, Publications, London, IBP, n.8. $214 \mathrm{pp}$.

Gomes, L.C.; Baldisserotto,B.; Senhorini,J.A. 2000. Effect of stocking density on water quality, survival, and growth of larvae of the matrinxã, Brycon cephalus (Characidae), in ponds. Aquaculture, 183: 73-81.

Goulding, M. 1980. The Fishes and Forest, Explorations in Amazonian Natural History. University of California Press, Berkeley, USA. $280 \mathrm{p}$.

Graef, E. W.; Resende, E. K.de, Petry, P.; Storti-Filho, A. 1987. Policultivo de matrinchã (Brycon sp) e jaraqui (Semaprochilodus sp) em pequenas represas. Acta Amazônica, v16/17, n. único. p. 33-42.

Graef, E. W. 1993.Considerações sobre a prática da piscicultura no Amazonas. Bases Científicas para Estratégias de Preservação e Desenvolvimento da Amazônia. Ferreira, E.J.G.; Santos, G.M. dos; Leão, E.L.M. e Oliveira, L.A. (ed) vol. 2. INPA. Manaus, AM. p. 345-360.

Guimarães, S. F. e Storti-Filho, A. 1997. The effects of temperature on survival of young Matrinchã (Brycon cephalus) under laboratory conditions. Anais do Internacional Symposium Biology of Tropical Fishes, Manaus, AM. p. 41.

Honczaryk, A. 2000. Efeitos da densidade de estocagem sobre performance do Matrinxã, Brycon cephalus Günther, 1869 (Teleostei, Characidae). Anais do VIII Simpósio Brasileiro de Aqüicultura/III Encontro Brasileiro de Patologia de Organismos Aquáticos. Piracicaba: Fundação de Estudos Agrários Luiz de Queiroz, p.165 - 175

Hoshiba, M.A.; Ganeco, L.N. Senhorini, J.A; Urbinatti, E.C. 2007. Utilização do triptofano no enriquecimento da ração na larvicultura de matrinxã (Brycon amazonicus). Anais da 44a. Reunião Anual da Sociedade Brasileira de Zootecnia, Jaboticabal,SP.1 CD- room.

Howes, G.L. 1982. Review of de genus Brycon (Teleostei,Characidae). Bull.Br.Mus. Nat. Hist. Zool, v.43.n1. p. 1-47.

Ishiwata, N. 1968 .Ecological studies on the feeding of fishes. IV Satiation curve. Bull Jpn. Soc. Sci. Fish, 34. p. 691-693.

Ivlev, V.S. 1961. Experimental ecology of the feeding of fishes. Yale University Press,New Haven,C.T. 302 p.

Izel, A. C. U., Perin, R.; Melo, L. A. S. 1996. Desempenho de matrinxã (Brycon cephalus) submetidos a dietas com diferentes níveis protéicos na Amazônia Central. Anais da XXXII Reuniāo Anual da Sociedade Brasileira de Zootecnia, Fortaleza. p. 258259.

Izel, A. C. U.; Pereira-Filho,M.; Melo,L.A.S.; Macedo,J.L.V. 2004. Avaliação de níveis protéicos para nutrição de juvenis de matrinxã (Brycon cephalus). Acta Amazônica, vol.34(2). p 179-184.

Jarboe, H. H.; Grant, W. J. 1996 . Effects of feeding time and frequency on growth of channel catfish Ictalurus punctatus in closed recirculating raceway systems. Journal Word Aquacult. Soc., v. 27, n.2. p. 235-239.

Jobling, M.1983. Effect of feeding frequency on food intake and growth of Artic Charr, Salvelinud alpinus L. Journal Fish Biological, 23. p. 177-185.

Kubitza, F. 1997. Qualidade do alimento, qualidade da água e manejo alimentar na produção de peixes. Anais do Simpósio sobre manejo e nutrição de peixes. CBNA, Piracicaba, SP. p. 63-101.

Leite, R.G. 2004. A alimentação de juvenis de matrinxã,Brycon amazonicus (Pisces,Characidae), em áreas inundadas da Ilha de Marchantaria,Amazonas,Brasil. Acta Amazônica. vol.34(4). p.661-664.

Lima, F. C. T. 2003. Subfamily Bryconinae (Characins, Tetras) In: Reis, R.E., S.O.; Kullander, C.J. Ferraris Jr.,C.J. (Orgs.). Check list of the freshwater of South and Central America. EDIPUCRS, PORTO ALEGRE:174-181. 
Maragoudaki, D.; Paspatis, M.; Kentouri, M. 1997. Response of Pagrus pagrus to restrictive self-feeding regime. Voluntary-food intake in fish. Houlihan, D.; Kiessling, A.; Boujard, T. ed. p. 30.

Mendonça, J. O. J.; Senhorini, J. A.; Fontes, N. A.; Cantelmo, O. 1993. A. Influência da fonte protéica no crescimento do Matrinchã, Brycon cephalus em viveiros. Bol. Téc. CEPTA, Pirassununga, SP, v.6, n1. p. 51-57.

Nagata, N. 1989. Satiation and Gastric Evacuation in Juvenile Manu Salmon. Nippon Suisan Gakaishi, 55, 9. p. 1523-1528.

Pezzato L.E.; Barros, M.M.; Carratore, C.R.Del; Salaro,A.L.; Oliveira,M.C.B.; Rosa, G.J.M. 2000. Avaliação do matrinxã, Brycon cephalus mantidos sob condições de clima tropical. Anais do VIII Simpósio Brasileiro de Aqüicultura/III Encontro Brasileiro de Patologia de Organismos Aquáticos. Piracicaba: Fundação de Estudos Agrários Luiz de Queiroz, p.177-181.

Pizango-Paima, E.G.; Pereira-Filho,M.; Oliveira-Pereira, M.I. Composição corporal e alimentar do matrinxã Brycon cephalus, (GÜNTHER, 1869), na Amazônia Central. Acta Amazônica, vol.31(3).p. 509-520.

Romagosa, E.; Ayroza, L. M. S; Scorvo Filho, J. D.; Frascá-Scorvo, C. M. D. 1998. Influência da aeração no crescimento e engorda do matrinxã, Brycon cephalus, (GÜNTHER, 1869) (PISCES, TELEOSTEI) em viveiros. Bol. Téc. CEPTA, Pirassununga, SP. p.49-58.

Salum , W.B.; Bertechini, A.G.; Cantelmo O. Â.; Pezzato L. E.; Logato, P. R. V. 2002. Coeficiente de digestibilidade aparente da matéria seca, proteína bruta e extrato etéreo de ingredientes de ração para o matrinchã (Brycon cephalus, GÜNTHER 1869) (TELEOSTEI, CHARACIDAE). Ciênc. agrotec., Lavras, v.26, n.1, p.174-181.

Saint-Paul, U.; Werder, U. 1977. Aspectos generales sobre a piscicultura en el Amazonas y resultados preliminares de experimentos de alimentácion de Brycon melanopterum con raciones peletizadas con diferentes composiciones. Anais do Simpósio de La Associación Latino Americana de Acuicultura, 1, Macaray, Venezuela. p.1-22.

Schimittou, H. P. 1993. High density fish culture in low volume cages. Singapore, American Soybean Association. 78 p.

Simpson, S.J. e Raubenheimer,D. 2001 A framework for the study of macronutrient intake in fish. Aquaculture Research. v(32), p.421-432.
Scorvo Filho, J. D, Martins, M.I.E.G., Frascá-Scorvo, C.M.D. 2004. Instrumentos para análise da competitividade na piscicultura In: Tópicos especiais em Piscicultura de Água Doce Tropical Intensiva. Cyrino, J.E. P. et al .ed, São Paulo, p 517-533.

Scorvo Filho, J. D.; Martins, N. B.; Ayrosa, L. M. S. 1998. Piscicultura em São Paulo: custos e retornos de diferentes sistemas de produção na safra de 1996/1997. Informaçôes Econômicas IEA, SP. v. 28, n.3. p. 41-60.

Singh, B. H.; Srivastava, A. K. 1984. Effects of feeding frequency on the growth, consumption and gross conversion efficiency in the Siluroid catfisf, Heteropneustes fossilis (Bloch). BAMIDGEH, v. 36, n.3. p. 80-89.

Singh, B. H.; Srivastava, A. K. 1985. Satiation, gastric evacuation and appetite revival in Heteropneustes fossilis (Bloch) (Siluriformes: Pisces). Aquaculture, 49. n.3/4. p. 307-313.

Soares, M. C. F. 1989. Estudos preliminares do cultivo do matrinxã Brycon cephalus - Günther, 1869) (Teleostei: Characidae). Aclimatação, crescimento e reprodução. Dissertação de Mestrado em Produção Animal - Instituto de Biologia da Universidade Federal da Bahia, Salvador, BA, 73 p.

Van-Der-Meer, M. B.; Van-Herwaarden, H; Verdegem, M. C. J. 1997. Effect of number of meal and frequency of feeding on voluntary feed intake of Colossoma macropomum (Cuvier). Aquaculture Research, v. 28, n.6. p. 419-432.

Vahl, O. 1979. An hypothesis on the control of food intake in fish. Aquaculture, 17. p.221-229.

Viantea-Arana, L. 1997. Princípios químicos da qualidade da água em aqüicultura: uma revisão para peixes e camaróes. Florianópolis, SC. Editora da EFSC. 166 p.

Webster, C. D.; Tidwell, J. H.; Yancey, D. H. 1992a. Effect of protein level and feeding frequency on growth and body composition of cage-reared chanel catfish. Prog.Fish Cult., v.54, n.2. p. 92-98.

Webster, C. D.; Tidwell, J. H.; Clark, J. A.; Yancey, D. H. 1992b. Effects of feeding diets contains 34 a $38 \%$ protein at two feeding frequencies on growth and body composition of channel catfish. Journal of Applied Aquaculture, 1. p. 67-80.

Recebido em 20/12/2006

Aceito em 10/09/2007 